Research Article

\title{
Roof Control Technology of Mining Roadway under the Influence of Advanced Supporting Pressure
}

\author{
Zhiyuan Jin $\mathbb{D}^{1},{ }^{1}$ Youlin $\mathrm{Xu},{ }^{1}$ Tao Peng $\mathbb{D}^{1,2}$ and Linsheng Gao ${ }^{3}$ \\ ${ }^{1}$ School of Mining Engineering, Guizhou Institute of Technology, Guiyang, Guizhou 550003, China \\ ${ }^{2}$ School of Resources \& Safety Engineering, Central South University, Changsha, Hunan 410083, China \\ ${ }^{3}$ School of Safety Engineering, North China Institute of Science and Technology, Langfang, Hebei 065201, China
}

Correspondence should be addressed to Tao Peng; pengxitong2018@163.com

Received 13 April 2021; Accepted 28 May 2021; Published 9 June 2021

Academic Editor: Dezhong Kong

Copyright (C) 2021 Zhiyuan Jin et al. This is an open access article distributed under the Creative Commons Attribution License, which permits unrestricted use, distribution, and reproduction in any medium, provided the original work is properly cited.

\begin{abstract}
In order to solve the problem of controlling the roof of the stoping roadway in 1204 fully mechanized face under the influence of advanced support pressure, according to the characteristics of the stoping roadway section, the single hydraulic prop and $\pi$-shaped steel beam were selected to verify the shrinkage of the single hydraulic support and establish mechanics. The model calculates that at least 3 single hydraulic props and at least 2 material lanes are required for the transportation lane; through the numerical simulation method, a reasonable roof control plan for the stoping roadway in the advance support section is determined, that is, $0 \sim$ in front of the material lane. The one-beam three-column method is adopted within $30 \mathrm{~m}$, and the row spacing is $0.8 \mathrm{~m}$; the one-beam four-pillar method is adopted within $0-20 \mathrm{~m}$ of the working front of the transportation lane; and the one-beam three-pillar method is adopted within $20-30 \mathrm{~m}$, and the row spacing is $0.8 \mathrm{~m}$. On-site industrial test practice proved that the proposed roof control scheme is reasonable, and the roadway section can meet the actual production requirements.
\end{abstract}

\section{Introduction}

Under the action of the advanced supporting pressure, the mining roadway will experience roof subsidence, bottom heave, and two-side shrinkage deformation so that the section of the mining roadway cannot meet the actual production requirements and affects the normal mining of the coal mining face. There are many technologies for the roof control of mining roadways. For example, Sun Jiuzheng published the book "Control Technology and Engineering Practice of Thin Composite Roof of Mining Roadways," which discussed the mechanical characteristics, changing laws, and influencing factors of thin composite roofs of mining roadways. The deformation and failure mechanism of the thin composite roof of the roadway and the deformation and failure laws of the thin composite roof of the mining roadway are summarized. Qiu Wenhua et al. proposed roof control technology for semicoal and rock roadways under complex conditions. Due to the different production geological conditions of each mining area, the roof control technology of the fully mechanized mining face is different under the influence of the advanced support pressure. According to the specific production conditions of the 1204 working face, relevant research is carried out to put forward a reasonable technical plan for the roof control of the mining roadway in the fully mechanized mining face.

\section{Engineering Geological Conditions}

The 1204 working face is arranged in the 2 \# coal seam, the ground elevation is $+948 \sim+1103 \mathrm{~m}$, the underground elevation is $+495 \sim+541 \mathrm{~m}$, the strike length is $1980 \mathrm{~m}$, and the dip length is $167 \mathrm{~m}$. The thickness of the coal seam is 2.5 to $3.95 \mathrm{~m}$, with an average of $3.2 \mathrm{~m}$; the inclination angle of the coal seam is $3^{\circ}$ to $8^{\circ}$, with an average of $6^{\circ}$. The occurrence of roof and floor is shown in Table 1. 
TABLE 1: The lithology of the roof and floor.

\begin{tabular}{lccc}
\hline Roof and floor name & Rock name & Thickness $(\mathrm{m})$ & Lithology \\
\hline Basic top & Sandy shale argillaceous shale & 6.5 & Dense and hard, not easy to fall \\
Direct top & Partially sandy shale & 1.6 & Broken, cracks developed, easy to straddle \\
Pseudotop & Mudstone & 0.2 & Fall with the mining \\
Direct bottom & Sandy shale & 2.4 & Siltstone lenticular horizontal bedding with fissures \\
Old bottom & Fine-grained sandstone & 2.42 & Horizontal bedding fissures are developed and hard, $f=6$ or so \\
\hline
\end{tabular}

\section{Determination of the Key Parameters of the Roof Control of the Mining Roadway}

According to the production geological conditions of 1204, the roof control mode of the advanced support section of the super 1204 fully mechanized face is determined to be "single hydraulic prop $+\pi$ beam".

\subsection{Single Hydraulic Prop and $\pi$-Shaped Steel Beam Selection.} According to the cross section characteristics of the two lanes in the 1204 working face, the single hydraulic prop of the transportation lane uses the DZ-35 type, and the $\pi$-shaped steel beam uses the DFB4000-300 type. The single hydraulic prop of the material lane is DZ-28, and the $\pi$-shaped steel beam is DFB3600-300. The main technical characteristics of the single hydraulic prop and the $\pi$-shaped steel beam are shown in Tables 2 and 3, respectively.

3.2. Verification of the Shrinkage of Single Hydraulic Support. After the roadway is excavated, the basic support is performed, and the initial deformation of the old roof is given [1]. The allowable shrinkage amount should satisfy the movement and development of the old roof and reach the final stable state, that is, the basic support of the roadway. The allowable roof shrinkage of the protective structure should at least meet the expected deformation of the surrounding rock $[2,3]$.

$$
\Delta h+\Delta h_{j}>\Delta h_{0}
$$

where $\Delta h$ is the required shrinkage of the basic support in the lane, $\Delta h_{j}$ is the amount of compression of the auxiliary supporting structure, and $\Delta h_{0}$ is the moving amount of the roof and floor of the roadway under a given deformation state of the old roof, generally $200 \sim 300 \mathrm{~mm}$.

The roof control method of the roadway in 1204 fully mechanized coal mining face adopts "single hydraulic prop $+\pi$ beam," the compression of the auxiliary support structure is 0 , and the estimated roadway roof and floor moving in the given deformation state of the old roof is $300 \mathrm{~mm}$. The required shrinkage of the basic stent should be greater than $300 \mathrm{~mm}$. The selected single hydraulic prop has a stroke of $800 \mathrm{~mm}$, which can meet the requirements.

3.3. Supporting Density of Single Hydraulic Prop. According to the supporting force of the single hydraulic prop under the given deformation of the old roof and the given load of the roof, the bearing capacity of the $\pi$-shaped beam is considered, and the supporting density is determined by comprehensive analysis.

3.3.1. Under a Given Deformation State. Under the given deformation working condition required by the old roof, the supporting structure in the roadway should control the direct roof and make it close to the old roof. Therefore, the supporting force should be at least sufficient to balance the rock weight of the direct roof.

$$
N=10 \lambda \gamma h B d,
$$

where $N$ is the supporting force, $\mathrm{kN} ; \lambda$ is the dynamic pressure coefficient, $2 ; \gamma$ is the bulk density of the direct roof, $2.5 \mathrm{t} / \mathrm{m}^{3} ; h$ is the thickness of the direct roof, $1.6 \mathrm{~m}$; $d$ is row spacing, $0.8 \mathrm{~m}$; and $B$ is the width of the lane, the transportation lane is $5 \mathrm{~m}$, and the material lane is $4 \mathrm{~m}$.

It is calculated that the required supporting force $N=320 \mathrm{kN}$ for the transportation lane and the required supporting force $N=256 \mathrm{kN}$ for the material lane. Therefore, in this case, the transport lane needs at least 2 single hydraulic props and at least 2 material lanes.

3.3.2. Under a Given Load State. Since the roof falling shape is arched, it is analyzed according to Platts' pressure-free arch theory [4], as shown in Figure 1.

The damage range of the roadway gang is given by [5]

$$
C=\left(\frac{k_{c} r H v}{1000 \sigma_{m}}-1\right) h \tan \left(45^{\circ}-\frac{\phi}{2}\right) \text {. }
$$

In the above formula, the squeezing stress concentration coefficient around the roadway is generally taken as $3 ; r$ is the average gravity density of the rock formation, which is $25 \mathrm{kN} / \mathrm{m}^{3} ; v$ is the mining influence coefficient, $2 ; H$ is the buried depth and the maximum value is $487 \mathrm{~m}$; $\sigma_{m}$ is the uniaxial compressive strength of the top plate, $20 \mathrm{MPa} ; \phi$ is the internal friction angle of the top plate, $20^{\circ}$; and $h$ is the height of the roadway, the transportation lane is $3.1 \mathrm{~m}$, and the material lane is $2.5 \mathrm{~m}$.

By using formula (3), the damage range of the transportation lane ledge is calculated as $2.99 \mathrm{~m}$ and the damage range of the material lane ledge is calculated as $2.41 \mathrm{~m}$. by [6]

The maximum loosening range of the top plate is given

$$
b=\frac{L / 2+C}{f_{m}}
$$


TABLE 2: The main technical characteristics of single hydraulic prop.

\begin{tabular}{|c|c|c|c|c|c|c|c|c|}
\hline Model & $\begin{array}{l}\text { Rated work } \\
\text { resistance }(\mathrm{kN})\end{array}$ & $\begin{array}{c}\text { Rated work } \\
\text { hydraulic }(\mathrm{MPa})\end{array}$ & $\begin{array}{c}\text { Setting } \\
\text { force }(\mathrm{kN})\end{array}$ & $\begin{array}{l}\text { Pump station } \\
\text { hydraulic }(\mathrm{kN})\end{array}$ & $\begin{array}{c}\text { Maximum } \\
\text { height }(\mathrm{mm})\end{array}$ & $\begin{array}{c}\text { Minimum } \\
\text { height }(\mathrm{mm})\end{array}$ & $\begin{array}{l}\text { Stroke } \\
(\mathrm{mm})\end{array}$ & $\begin{array}{l}\text { Stroke base } \\
\text { area }\left(\mathrm{cm}^{2}\right)\end{array}$ \\
\hline DZ-35 & 200 & 25.5 & $118 \sim 157$ & $15 \sim 20$ & 3500 & 2700 & 800 & 113 \\
\hline DZ-28 & 250 & 31.8 & $118 \sim 157$ & $15 \sim 20$ & 2800 & 2000 & 800 & 113 \\
\hline
\end{tabular}

TABLE 3: The main technical characteristics of $\pi$ type steel beam.

\begin{tabular}{|c|c|c|c|c|c|c|}
\hline Model & Material & Width $(\mathrm{mm})$ & Length (mm) & $\begin{array}{c}\text { Height } \\
(\mathrm{mm})\end{array}$ & Thickness (mm) & Bearing capacity $(\mathrm{kN})$ \\
\hline $\begin{array}{l}\text { DFB4000-300 } \\
\text { DFB3600-300 }\end{array}$ & $27 \operatorname{simn}$ & 100 & $\begin{array}{l}4000 \\
3600\end{array}$ & 90 & 8 & $\begin{array}{l}300 \sim 400 \text {, that is, when the beam span is } \\
700 \mathrm{~mm} \text {, concentrated load at beam center }\end{array}$ \\
\hline
\end{tabular}

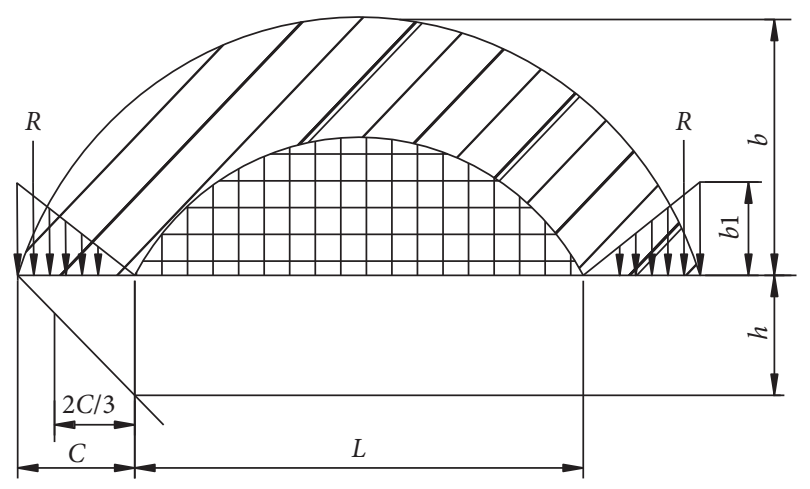

FIgURE 1: The map of roof caving arch.

where $f_{\mathrm{m}}$ is roof rigidity coefficient, taking 2 , and $L$ is the width of the lane. The transportation lane is $5 \mathrm{~m}$, and the material lane is $4 \mathrm{~m}$.

By using formula (4), the loosening range of the roof of the transportation lane is calculated as $2.74 \mathrm{~m}$ and the loosening range of the roof of the material lane is calculated as $2.21 \mathrm{~m}$.

Considering the most dangerous situation, the weight of the rock mass within the loose roof range is borne by the single hydraulic prop. The required single hydraulic prop supporting force is given by

$$
N=b r(2 C+L) d \text {. }
$$

By using formula (5), the supporting force of the single hydraulic prop required by the transportation lane is calculated as $603 \mathrm{kN}$ and the supporting force of the single hydraulic prop required by the material lane is calculated as $389 \mathrm{kN}$. Therefore, in this case, at least 3 single hydraulic props are required for the transportation lane and at least 2 for the material lane.

3.3.3. Considering the Bearing Capacity of $\pi$-Shaped Steel Beams. Since the length of the $\pi$-shaped beam is much larger than that of the hinged top beam, its overall supporting effect is good, which avoids the phenomenon of large top pressure and wedge pressing on the hinged top beam [7-12]. When the roof control mode is one beam and two columns, it is simplified as a simply supported beam for calculation, as shown in Figure 2(a); when the roof control mode is one beam and three columns, it is simplified as a statically indeterminate beam for calculation as shown in Figure 2(b).

When the roof control mode is one beam and two columns, it satisfies

$$
[\sigma]=\frac{M_{\max }}{W_{z}}=\frac{1 / 8 \cdot q \cdot L^{2}}{W_{z}}=\frac{1 / 8 \cdot F \cdot L}{W_{z}} .
$$

When the roof control mode is one beam and three columns,

$$
[\sigma]=\frac{M_{\max }}{W_{z}}=\frac{9 / 512 \cdot q \cdot L^{2}}{W_{z}}=\frac{9 / 512 \cdot F \cdot L}{W_{z}},
$$

where $[\sigma]$ is the allowable stress, $\mathrm{MPa} ; M_{\max }$ is the maximum bending moment, $\mathrm{kN}^{*} \mathrm{~m} ; W_{Z}$ is the bending section modulus, $\mathrm{m} 3 ; q$ is the uniform load, $\mathrm{kN} / \mathrm{m}$; $L$ is beam span, $\mathrm{m}$; and $F$ is the equivalent concentrated force, $\mathrm{kN}$.

It can be seen from Table 2 that when the beam span is $700 \mathrm{~mm}$, the central load of the beam is $300-400 \mathrm{kN}$. Since the $\pi$-shaped steel beam $[\sigma]$ and $W_{\mathrm{Z}}$ are constants, the bearing capacity of the $\pi$-shaped steel beam at different individual hydraulic prop spacings is obtained (see Table 4).

The calculation results in Table 4 show that when the roof control mode is one beam and two columns, the bearing capacity of the $\pi$-shaped steel beam is less than the required supporting force $\mathrm{N}$ under the given deformation of the old roof and the given load state of the roof; when the roof control mode is one beam and three columns, the bearing capacity of the $\pi$-shaped steel beam in the material lane can meet the requirements, and the bearing capacity of the $\pi$-shaped steel beam in the area affected by the weak forward supporting pressure of the transportation lane can also meet the design requirements, but the loading capacity of the $\pi$-shaped steel beam in the severely affected area 


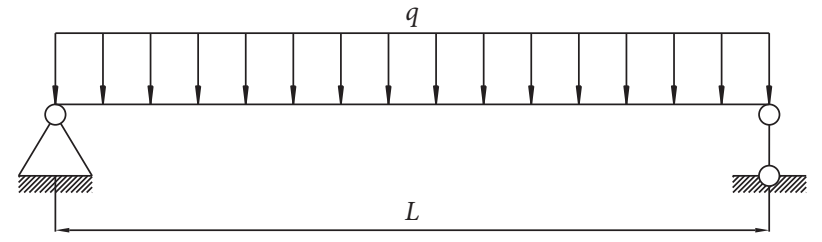

(a)

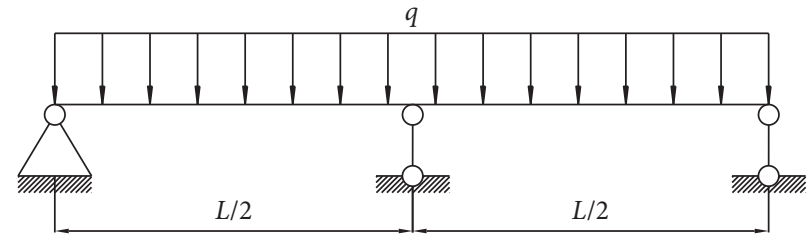

(b)

Figure 2: The advanced support simplified mechanical model. (a) One beam and two columns. (b) One beam and three columns.

TABLE 4: The carrying capacity of $\pi$ type steel beam in different spans.

\begin{tabular}{lccc}
\hline \multirow{2}{*}{ Mode } & \multicolumn{3}{c}{ Beam span $(\mathrm{mm})$} \\
& $4000(\mathrm{kN})$ & $3600(\mathrm{kN})$ & $700(\mathrm{kN})$ \\
\hline One beam and two columns & 52.5 & 58.3 & 400 \\
One beam and three pillars & 373 & 415 & \\
\hline
\end{tabular}

of the transportation lane cannot satisfy the design requirements.

\section{Research and Demonstration of Roof Control Scheme}

4.1. Feasible Plan. In order to further determine the roof control plan of the stoping roadway in 1204 fully mechanized mining face, the influence range of the advanced support is considered as $30 \mathrm{~m}$. Due to the different section sizes of the transportation lane and the material lane, four feasible plans are proposed, respectively. Under the normal mining situation of the simulation study, different methods are adopted. When the advance support plan is used, the surrounding rock deformation law and plastic zone distribution characteristics of the two lanes are used to optimize and determine the reasonable roof control plan of the mining roadway. The specific plan is as follows.

\subsubsection{Material Lane}

Option 1: the roof control of the mining roadway adopts one beam and three pillars, and the row spacing is $1.6 \mathrm{~m}$

Option 2: the roof control of the mining roadway adopts the one-beam three-pillar method, and the row spacing is $0.8 \mathrm{~m}$

Option 3: the roof control of the mining roadway adopts one beam and three pillars, and the row spacing is $0.4 \mathrm{~m}$

Option 4: the roof control of the mining roadway adopts the one-beam four-pillar method, and the row spacing is $0.8 \mathrm{~m}$

\subsubsection{Transportation Lane}

Option 1: the roof control of the mining roadway adopts one beam and three pillars, and the row spacing is $1.6 \mathrm{~m}$
Option 2: the roof control of the mining roadway adopts the one-beam three-pillar method, and the row spacing is $0.8 \mathrm{~m}$

Option 3: the roof control of the mining roadway adopts one beam and four pillars, and the row spacing is $0.8 \mathrm{~m}$

Option 4: the roof control of the mining roadway adopts the one-beam four-pillar method within 0-20 m from the working face, and one-beam three-pillar method within $20-30 \mathrm{~m}$, and the row spacing is $0.8 \mathrm{~m}$

4.2. Plan Demonstration and Determination. With the help of FLAC ${ }^{3 D}$ software, the above feasibility schemes are researched and demonstrated. Establish a horizontal model, excavate $80 \mathrm{~m}$, and arrange surface displacement measurement points in two lanes $50 \mathrm{~m}$ ahead of the work face, as shown in Figure 3. By comparing and analyzing the deformation law of the surrounding rock of the mining roadway and the distribution characteristics of the plastic zone in different schemes, the reasonable advance support technical scheme is optimized and determined $[13,14]$.

4.2.1. Material Lane. The plastic zone distribution of surrounding rock under different schemes is shown in Figure 3, and the surface displacement characteristics of the transportation lane under different schemes are shown in Table 5.

From the analysis in Figure 3, it can be seen that when option 1 is adopted, the distribution range of the plastic zone of the surrounding rock of the material lane is obviously larger than that of options 2, 3, and 4, while when the option 2,3 , and 4 are adopted, the distribution range of the plastic zone of the surrounding rock of the material lane is similar. It means that the roof of the roadway in the advanced support section of the working face has been effectively controlled when the second, third, and fourth options are adopted, but the first-time control effect of the program is poor.

From the analysis of Figure 3 and Table 5, it can be seen that when the first scheme is adopted, the roof control mode of the mining roadway is one beam and three columns, the row spacing is $1.6 \mathrm{~m}$, and the cumulative displacement of the roof and floor and the cumulative displacement of the two sides have reached $460 \mathrm{~mm}$ and $501 \mathrm{~mm}$, respectively. When the second scheme is adopted, the roof control method of the mining roadway remains unchanged, and the row spacing becomes $0.8 \mathrm{~m}$. Compared with the first scheme, the cumulative displacement of the roof and floor and the 


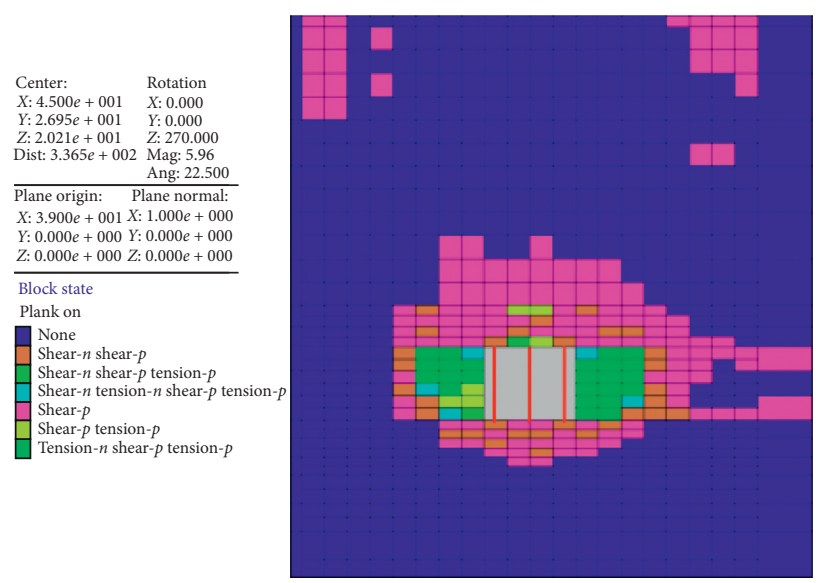

(a)

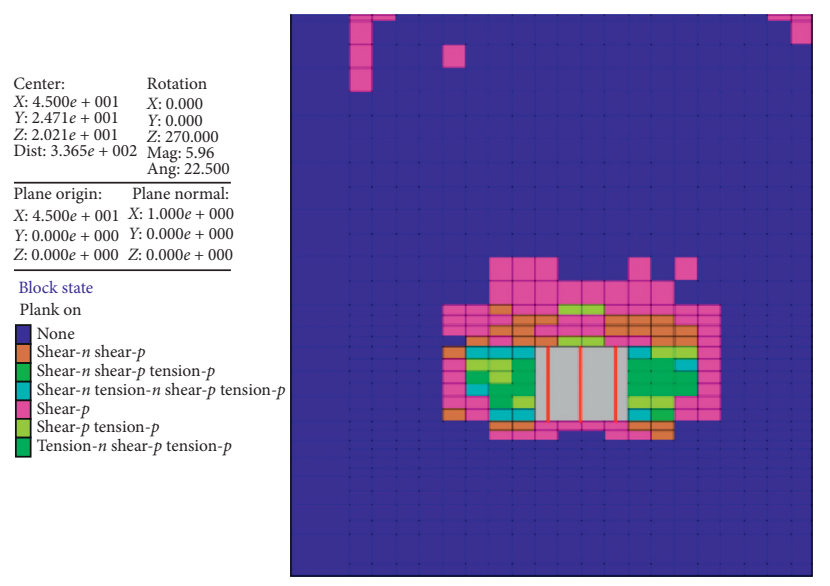

(c)

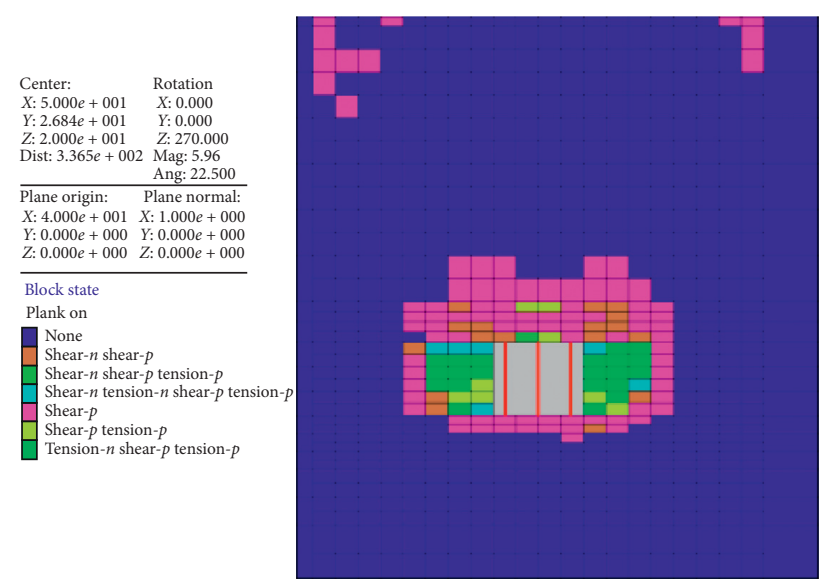

(b)

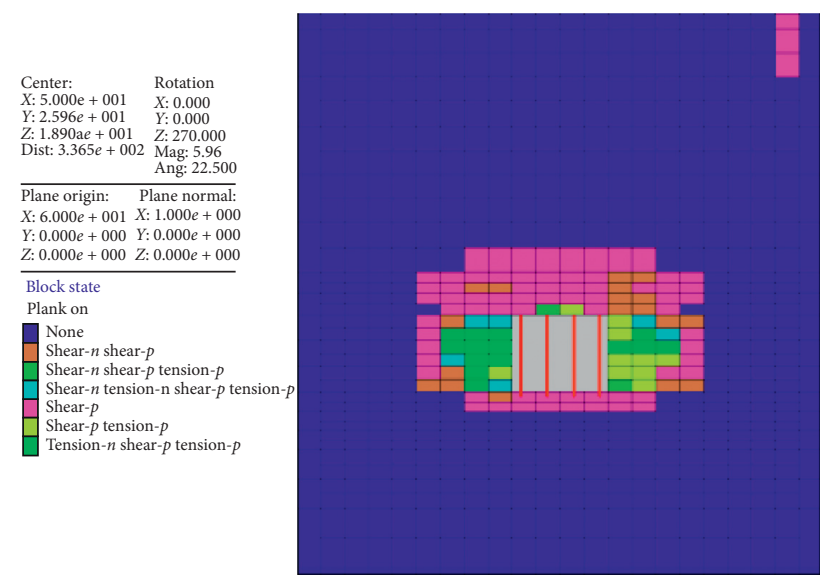

(d)

Figure 3: Plastic zone distribution of the material roadway's surrounding rock. (a) Option 1. (b) Option 2. (c) Option 3. (d) Option 4.

TABLE 5: The displacement curve about the material roadway's surface in different advanced support schemes.

\begin{tabular}{lcc}
\hline Option & \multicolumn{2}{c}{$\begin{array}{c}\text { Cumulative displacement }(\mathrm{mm}) \\
\text { Top and bottom }\end{array}$} \\
\hline 1 & 460 & 501 \\
2 & 299 & 331 \\
3 & 273 & 303 \\
4 & 281 & 311 \\
\hline
\end{tabular}

cumulative displacement of the two sides are reduced by $179 \mathrm{~mm}$ and $170 \mathrm{~m}$ respectively; when the scheme is adopted at 3 o'clock, the roof control method of the mining roadway remains unchanged, and the row spacing becomes $0.4 \mathrm{~m}$. However, compared with the second plan, the cumulative displacement of the roof and floor and the cumulative displacement of the two sides are only reduced by $26 \mathrm{~mm}$ and $28 \mathrm{~mm}$, respectively. In the fourth plan, the roof control mode of the mining roadway becomes one beam and four columns with a row spacing of $0.8 \mathrm{~m}$. Compared with the second plan, the cumulative displacement of the roof and floor and the cumulative displacement of the two sides are only reduced by $18 \mathrm{~mm}$ and $20 \mathrm{~mm}$, respectively, which shows reducing the spacing between rows can improve the roof control effect of the advanced support section. However, the simulation study shows that the material lane roof is effectively controlled when the second, third, and fourth options are adopted, but the effect is not much different. The ratio control effect is very obvious; therefore, the second option is determined as the optimal one.

4.2.2. Transportation Lane. The plastic zone distribution of surrounding rock under different schemes is shown in Figure 4, and the surface displacement characteristics of the transportation lane under different schemes are shown in Table 6.

From the analysis in Figure 4, it can be seen that when the transportation lane adopts Option 1, the plastic zone of the surrounding rock is the largest, followed by Option 2, the smallest in Option 3 and Option 4, and when Option 3 and Option 4 are adopted, the distribution range of the plastic zone of the surrounding rock of the material roadway is not much different. The distribution range is not much different, indicating that when schemes 3 and 4 are adopted, the roadway roof control effect in the advanced support section of the working face is better.

From the analysis of Figure 4 and Table 6, it can be seen that when the first scheme is adopted, the roof control mode of the mining roadway is one beam and three columns, the 


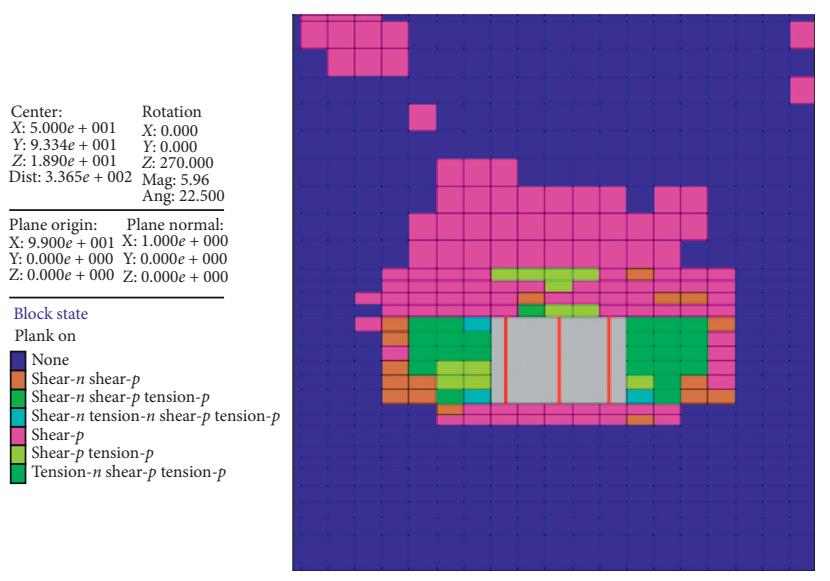

(a)

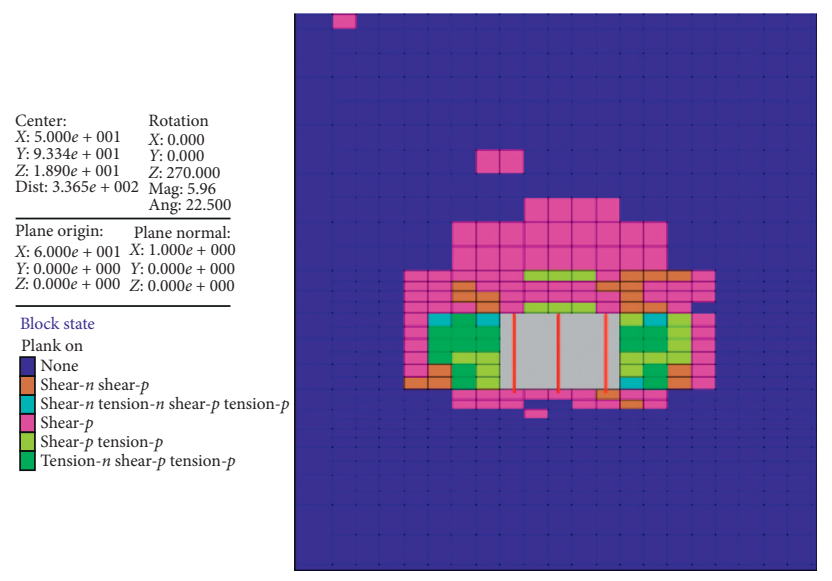

(c)

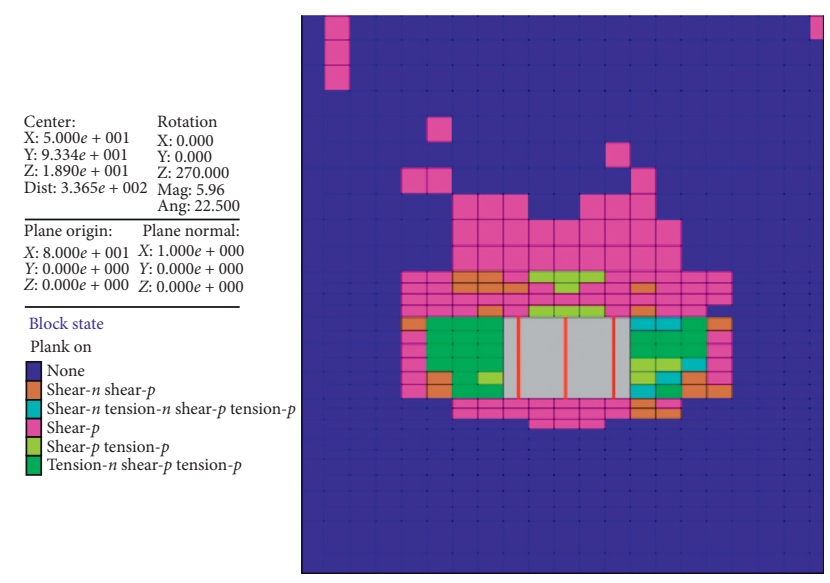

(b)

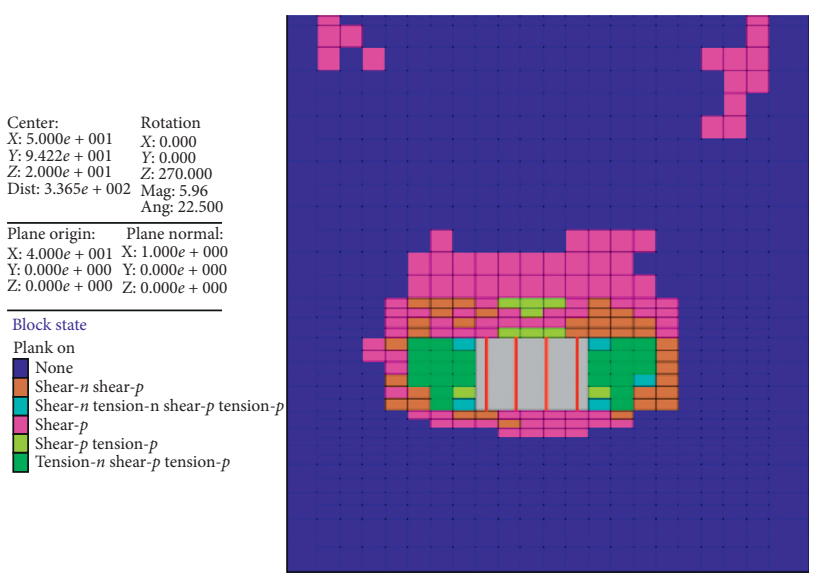

(d)

Figure 4: Plastic zone distribution of the surrounding rock. (a) Option 1. (b) Option 2. (c) Option 3. (d) Option 4.

TABLE 6: The displacement curve about transportation roadway surface in different advanced support schemes.

\begin{tabular}{lcc}
\hline \multirow{2}{*}{ Serial number } & \multicolumn{2}{c}{ Cumulative displacement $(\mathrm{mm})$} \\
& Top and bottom & Two gangs \\
\hline Option 1 & 511 & 589 \\
Option 2 & 403 & 451 \\
Option 3 & 337 & 389 \\
Option 4 & 321 & 377 \\
\hline
\end{tabular}

row spacing is $1.6 \mathrm{~m}$, and the cumulative displacement of the roof and floor and the cumulative displacement of the two sides reach $511 \mathrm{~mm}$ and $589 \mathrm{~mm}$, respectively. When the second plan is adopted, the advance support method remains unchanged, and the row spacing becomes $0.8 \mathrm{~m}$. Compared with the first plan, the cumulative displacement of the top and bottom plates and the cumulative displacement of the two sides are reduced by $108 \mathrm{~mm}$ and $148 \mathrm{~mm}$, respectively; when the third is adopted at the same time, the advance support method remains unchanged, and the row spacing is changed to $0.4 \mathrm{~m}$. However, compared with the case of using the second scheme, the cumulative displacement of the top and bottom plates and the cumulative displacement of the two sides are only reduced by $66 \mathrm{~mm}$ and $62 \mathrm{~mm}$, respectively; when the fourth scheme is adopted and when the working front is $0-20 \mathrm{~m}$, one beam and four columns are used, and one beam and three columns are used within $20-30 \mathrm{~m}$, and the row spacing is $0.8 \mathrm{~m}$. Compared with scheme 3 , the cumulative displacement of the top and bottom plates and the cumulative displacement of the two sides are only reduced. The values of $16 \mathrm{~mm}$ and $12 \mathrm{~mm}$ indicate that the control effect of the surrounding rock in the advanced support section of the working face of scheme 3 and scheme 4 is better, but the difference in the control effect between the two is very small. Considering comprehensively, the fourth option is determined as the best option.

Therefore, the optimal design plan for the roof control of the mining roadway in 1204 fully mechanized mining face is determined as follows: (1) material lane: one beam and three columns are used within $0-30 \mathrm{~m}$ in front of the work face, with a row spacing of $0.8 \mathrm{~m}$; (2) transportation lane: when the working front is $0-20 \mathrm{~m}$, one beam and four columns are used inside, and one beam and three columns are used within $20-30 \mathrm{~m}$, and the row spacing is $0.8 \mathrm{~m}$.

\section{On-Site Industrial Test}

5.1. Station Layout. In order to verify the roof control effect of the mining roadway, the roadway surface displacement 


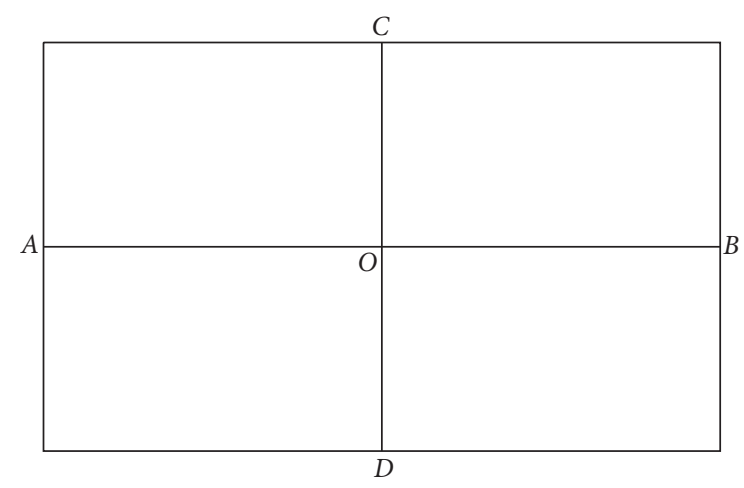

FIGURE 5: Sketch map of the displacement of tunnel surface.

observation stations were arranged in the transportation lane and the material lane, respectively, and the "cross measurement method" was used for observation. The measurement points are set up as shown in Figure 5. A drill hole with a depth of $400 \sim 500 \mathrm{~mm}$ is constructed on the top and bottom and the two sides, and a round steel or steel rod with a diameter of 16 18 $\mathrm{mm}$ is buried in the hole and fixed with a resin coil. The roadway shows that the displacement monitoring mainly includes roof subsidence OC, floor heave $\mathrm{OD}$, left side approach $\mathrm{OA}$, and right side approach $\mathrm{OB}$.

5.2. Analysis of Observation Results. Field measurements show that the cumulative approach of the two sides of the material lane is $477 \mathrm{~mm}$, the cumulative approach of the roof and floor is $411 \mathrm{~mm}$, the cumulative approach of the two sides of the transportation lane is $354 \mathrm{~mm}$, and the cumulative approach of the top and floor is $301 \mathrm{~mm}$. The roof of the mining roadway in 1204 fully mechanized mining face has been effectively controlled, and the roadway section can meet the actual production requirements.

\section{Conclusion}

(1) The roof control support equipment suitable for the mining roadway of 1204 fully mechanized mining face is determined, namely, the single hydraulic prop of the transportation lane is DZ-35, the $\pi$-shaped steel beam is DFB4000-300, the single hydraulic prop of the material lane is DZ-28 type, and $\pi$-shaped steel beam is DFB3600-300 type.

(2) According to the supporting force of the single hydraulic prop required under the given deformation of the old roof and the given load of the roof, and considering the bearing capacity of the $\pi$-shaped beam, comprehensive analysis is used to determine the supporting density, combined with FLAC ${ }^{3 \mathrm{D}}$ numerical simulation method. Research and demonstration of the roof control scheme of the mining roadway were carried out, and the optimal scheme was determined, that is, the severely affected area within the advanced support range of the transportation lane adopts the one-beam four-pillar method, and the weakly affected area within the advanced support range of the material lane adopts the one-beam three-column method.

(3) Field engineering tests show that it is reasonable to propose the roof control plan of the stoping roadway in 1204 fully mechanized mining face. The cumulative approach of the two sides of the material roadway is $477 \mathrm{~mm}$, the cumulative approach of the roof and floor is $411 \mathrm{~mm}$, and the cumulative approach of the two sides of the transportation lane is $354 \mathrm{~mm}$. The cumulative moving distance of the roof and floor is $301 \mathrm{~mm}$, and the roof of the mining roadway is effectively controlled.

\section{Data Availability}

The data used to support the findings of this study are included within the article.

\section{Conflicts of Interest}

The authors declare that they have no known conflicts of interest that could influence the work reported in this study.

\section{Acknowledgments}

This research was supported by projects supported by the National Natural Science Foundation of China (51764010 and 5184109), Science and Technology Programs of Guizhou Province (Qiankehe Platform Talent [2019] 5674), and Guizhou Province Basic Research (Science and Technology Fund) Project (Qiankehe Foundation [2020] 1Y215).

\section{References}

[1] Z. Q. Song, Practical Mine Pressure Control, China University of Mining and Technology Press, Xuzhou, China, 1988.

[2] Z. Q. Song, J. Q. Jiang, and Y. X. Liu, "The appearance of underground pressure across mining roadways and uphill and the reasonable layout of roadways," Coal Science and Technology, vol. 5, pp. 60-61, 1987.

[3] Z. Q. Song, J. Q. Jiang, and Y. Song, "About mine pressure control design of stope roadway," Journal of Shandong Institute of Mining And Technology, vol. 3, pp. 1-11, 1985.

[4] L. W. Liu, Research On the Surface Subsidence Law of Shield Tunnel Construction of Subway in Composite Stratum, China University of Mining and Technology, Xuzhou, China, 2009.

[5] Y. X. Yu, Deformation and Failure Mechanism of Surrounding Rock of Rectangular Roadway and its Application in Wangcun Coal Mine, Xi'an University of Science and Technology, Xi'an, China, 2013.

[6] Y.X. Yu and S. C. Gu, "Research on measurement and control technology of loosening range of surrounding rock in rectangular roadway," Journal of Mining and Safety Engineering, vol. 6, pp. 828-835, 2013.

[7] L. S. Cao, "The application of $\pi$-shaped beam in the support of general mining face," Jiangxi Coal Science and Technology, vol. 3, pp. 34-35, 2010.

[8] F. Fan, "Application of $\pi$-shaped beam under broken roof," Jiangxi Coal Science and Technology, vol. 2, pp. 11-12, 2003. 
[9] C. Q. Wang, Y. H. Liu, and S. W. Lu, "Application of $\pi$-shaped beams in complex working faces," Modern Mining, vol. 3, pp. 101-102+127, 2012.

[10] D. Z. Kong, S. J. Pu, Z. H. Cheng, G. Y. Wu, and Y. Liu, "Coordinated deformation mechanism of the top coal and filling body of gob-side entry retaining in a fully mechanized caving face," International Journal of Geomechanics, vol. 21, no. 4, Article ID 04021030, 2021.

[11] S. Yang, H. Yue, G. Song, J. Wang, Y. Ma, and F. Liu, "3D physical modelling study of shield-strata interaction under roof dynamic loading condition," Shock and Vibration, vol. 2021, Article ID 6618954, 7 pages, 2021.

[12] J. F. Lou, F. Q. Gao, J. H. Yang et al., "Characteristics of evolution of mining-induced stress field in the longwall panel: insights from physical modeling," International Journal of Coal Science \& Technology, vol. 8, pp. 1-18, 2021.

[13] J. Z. Sun, Q. S. Wan, and Q. D. Liu, Thin Composite Roof Control Technology and Engineering Practice of Mining Roadway, Coal Industry Press, Beijing, China, 2008.

[14] W. H. Qiu, L. H. Kong, Y. Ou, H. H, and H. H. Wan, "Research on roof control technology of semi-coal and rock roadway under complex conditions," Coal Engineering, vol. 49, no. 11, pp. 45-49, 2017. 